\title{
MILITARY MULTIPURPOSE PYLON DEIGNED FOR 100TF LOAD
}

\author{
Adrian POPA, Ionuț-Cristian SCURTU, Beazit ALI, Marian RISTEA \\ "Mircea cel Bătrân" Naval Academy, Constanța, Romania \\ adrian.popa@anmb.ro
}

\begin{abstract}
The breakthrough in static structural, buckling and modal computer-simulated results can be used for new military purpose applications. The development of hardware resources leads to better simulation in mechanical analysis. Based on the Ansys software, the values presented for the pylon result from a complex analysis. The present paper aims at defining the working parameters for a specific load of $100 \mathrm{tf}$, as well as presenting the actual software capabilities for military applications. The information provided is valuable for the emerging technologies and the military techniques, being based on the ANSYS simulation.
\end{abstract}

\section{Keywords: multipurpose, pylon, Ansys, stress, load design}

\section{Introduction}

The multipurpose pylon presented in fig. 1 was designed in the Ansys Design Modeler and can be used in applications for antenna support, launching site for military apps, and easy to use fixture for offshore installations.

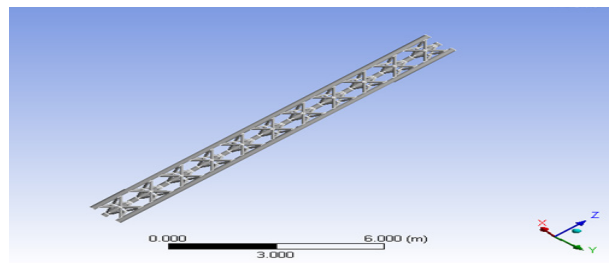

Fig.1. Geometry in Designmodeler

For the case study, we analysed the pylon, using the finite element method, with the software Ansys (fig.2), the height is 13.2 [m], the dimension used for triangle cross section is $1[\mathrm{~m}]$. The material properties are presented in table 1 .

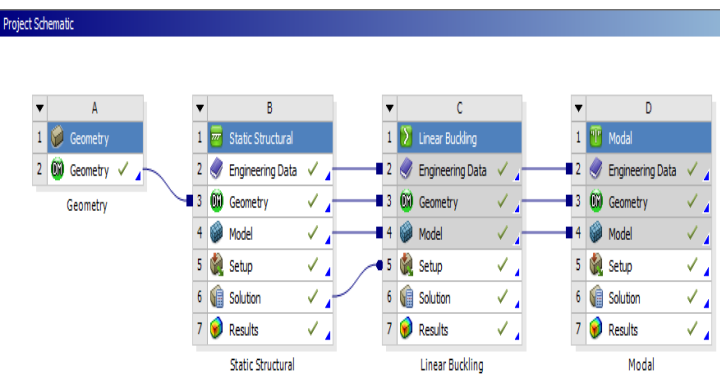

Fig.2. Project schematics

In this paper we will analyse the displacements and the von Mises Stress created by the load of $100 \mathrm{tf}$. The material used is naval steel with the characteristics presented in table 1.

Table 1 Material characteristics

\begin{tabular}{|l|r|l|}
\hline Elastic modulus & $2.10 \mathrm{E}+11$ & $\mathrm{~N} / \mathrm{m}^{\wedge} 2$ \\
\hline Poisson's ratio & 0.28 & $\mathrm{NA}$ \\
\hline Shear modulus & $2.35 \mathrm{E}+10$ & $\mathrm{~N} / \mathrm{m}^{\wedge} 2$ \\
\hline Mass density & 7700 & $\begin{array}{l}\mathrm{kg} / \mathrm{m}^{\wedge} \\
3\end{array}$ \\
\hline
\end{tabular}

Defining Geometry in Ansys software

The ANSYS software suite enables you to solve complex structural [1], [2] engineering problems such as linear buckling and vibration modes. Using the 
finite element analysis (FEA) from Ansys software, you can calculate and simulate the multi purpose pylon. For pylon analysis in Ansys, the model geometry parameters are presented in table 2. The Static Structural software module provides realism [2] in predicting the behavior and performance of pylon under specified load of $100 \mathrm{tf}$ in any military application.

Table 2 Geometry model

\begin{tabular}{|c|c|}
\hline Object Name & Geometry \\
\hline State & Fully Defined \\
\hline \multicolumn{2}{|l|}{ Definition } \\
\hline Type & DesignModeler \\
\hline Length Unit & Meters \\
\hline Element Control & Program Controlled \\
\hline Display Style & Body Color \\
\hline \multicolumn{2}{|l|}{ Bounding Box } \\
\hline Length X & $1.2 \mathrm{~m}$ \\
\hline Length Y & $1.066 \mathrm{~m}$ \\
\hline Length Z & $13.2 \mathrm{~m}$ \\
\hline \multicolumn{2}{|l|}{ Properties } \\
\hline Volume & $0.23266 \mathrm{~m}^{3}$ \\
\hline Mass & $1826.4 \mathrm{~kg}$ \\
\hline Scale Factor Value & 1. \\
\hline \multicolumn{2}{|l|}{ Statistics } \\
\hline Bodies & 1 \\
\hline Active Bodies & 1 \\
\hline Nodes & 1108129 \\
\hline Elements & 558752 \\
\hline Mesh Metric & None \\
\hline \multicolumn{2}{|l|}{ Basic Geometry Options } \\
\hline Parameters & Yes \\
\hline Parameter Key & DS \\
\hline Attributes & No \\
\hline Named Selections & No \\
\hline Material Properties & No \\
\hline \multicolumn{2}{|c|}{ Advanced Geometry Options } \\
\hline Use Associativity & Yes \\
\hline Coordinate Systems & No \\
\hline $\begin{array}{l}\text { Reader Mode Saves } \\
\text { Updated File }\end{array}$ & No \\
\hline Use Instances & Yes \\
\hline Smart CAD Update & No \\
\hline Compare Parts On Update & No \\
\hline Attach File Via Temp File & Yes \\
\hline Analysis Type & $3-\mathrm{D}$ \\
\hline $\begin{array}{l}\text { Decompose Disjoint } \\
\text { Geometry }\end{array}$ & Yes \\
\hline $\begin{array}{l}\text { Enclosure and Symmetry } \\
\text { Processing }\end{array}$ & Yes \\
\hline
\end{tabular}

Geometric parameters are automatically calculated in Ansys software for each part and the results are presented in table.3.

Table 3. Geometry parts

\begin{tabular}{|c|c|}
\hline Object Name & Solid \\
\hline State & Meshed \\
\hline \multicolumn{2}{|l|}{ Graphics Properties } \\
\hline Visible & Yes \\
\hline Transparency & 1 \\
\hline \multicolumn{2}{|l|}{ Definition } \\
\hline Suppressed & No \\
\hline Stiffness Behavior & Flexible \\
\hline Coordinate System & Default Coordinate System \\
\hline Reference Temperature & By Environment \\
\hline \multicolumn{2}{|l|}{ Material } \\
\hline Assignment & Structural Steel \\
\hline Nonlinear Effects & Yes \\
\hline Thermal Strain Effects & Yes \\
\hline \multicolumn{2}{|l|}{ Bounding Box } \\
\hline Length $X$ & $1.2 \mathrm{~m}$ \\
\hline Length Y & $1.066 \mathrm{~m}$ \\
\hline Length Z & $13.2 \mathrm{~m}$ \\
\hline \multicolumn{2}{|l|}{ Properties } \\
\hline Volume & $0.23266 \mathrm{~m}^{3}$ \\
\hline Mass & $1826.4 \mathrm{~kg}$ \\
\hline Centroid X & $2.1666 \mathrm{e}-007 \mathrm{~m}$ \\
\hline Centroid Y & $0.28868 \mathrm{~m}$ \\
\hline Centroid Z & $6.6 \mathrm{~m}$ \\
\hline Moment of Inertia Ip1 & $26823 \mathrm{~kg} \cdot \mathrm{m}^{2}$ \\
\hline Moment of Inertia Ip2 & $26823 \mathrm{~kg} \cdot \mathrm{m}^{2}$ \\
\hline Moment of Inertia Ip3 & $450.19 \mathrm{~kg} \cdot \mathrm{m}^{2}$ \\
\hline \multicolumn{2}{|l|}{ Statistics } \\
\hline Nodes & 1108129 \\
\hline Elements & 558752 \\
\hline
\end{tabular}

\section{Mesh}

Table 5. Model Mesh

\begin{tabular}{|l|l|}
\hline Object Name & Mesh \\
\hline State & Solved \\
\hline Defaults & \multicolumn{2}{|l|}{} \\
\hline Physics Preference & Mechanical \\
\hline Relevance & 100 \\
\hline Sizing & \\
\hline Use Advanced Size Function & Off \\
\hline Relevance Center & Coarse \\
\hline Statistics & \\
\hline Nodes & 1108129 \\
\hline Elements & 558752 \\
\hline
\end{tabular}

\section{Static structural}

Table 8 Model accelerations

\begin{tabular}{|l|l|}
\hline Object Name & Standard Earth Gravity \\
\hline State & Fully Defined \\
\hline Definition &
\end{tabular}




\begin{tabular}{|l|l|}
\hline $\begin{array}{l}\text { Coordinate } \\
\text { System }\end{array}$ & $\begin{array}{l}\text { Global Coordinate } \\
\text { System }\end{array}$ \\
\hline X Component & $0 . \mathrm{m} / \mathrm{s}^{2}($ ramped $)$ \\
\hline Y Component & $0 . \mathrm{m} / \mathrm{s}^{2}(\mathrm{ramped})$ \\
\hline Z Component & $-9.8066 \mathrm{~m} / \mathrm{s}^{2}($ ramped $)$ \\
\hline Suppressed & No \\
\hline Direction & $-Z$ Direction \\
\hline
\end{tabular}

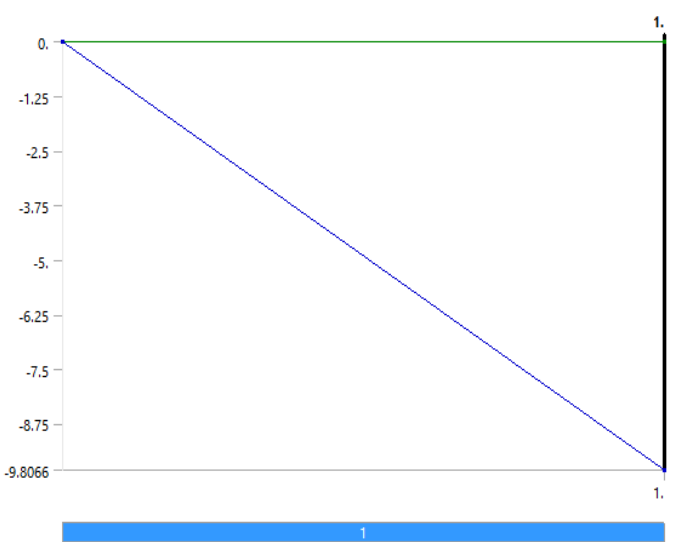

Fig.3 Standard Earth Gravity

Table 9 Static Structural Loads

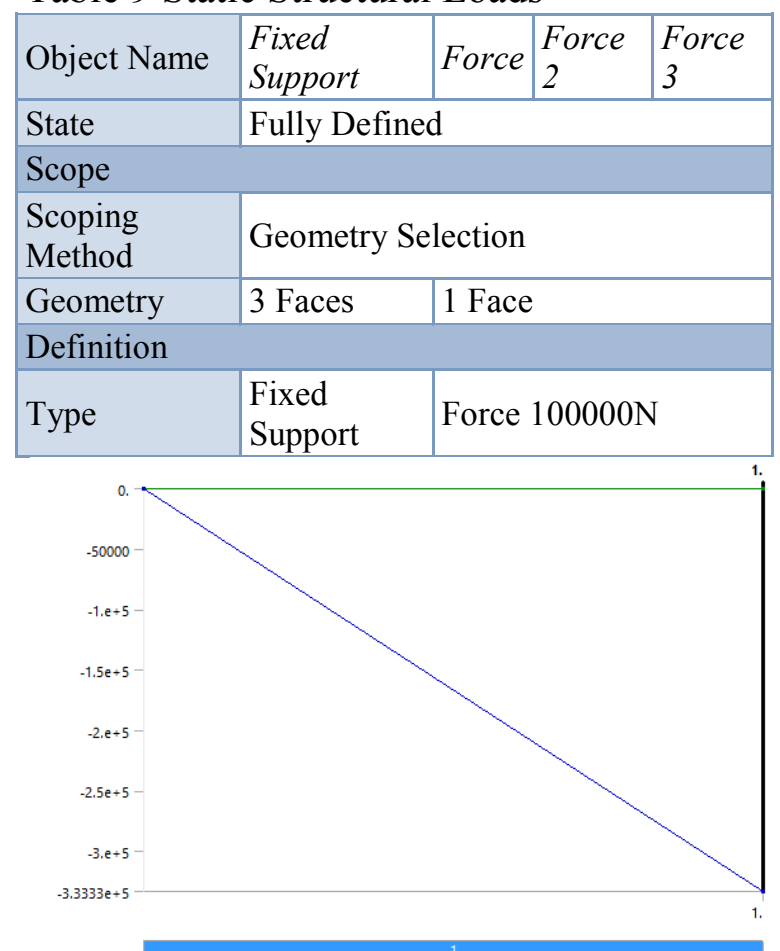

\section{Solution}

Fig. 4 Force in Static Structural

Calculations in Ansys Static Structural set as a convergence criterion the reduction of the maximum difference between consecutive iterations to $10^{-6}$ [3], [4]. The mesh shown below will interfere in the solution calculus. The solver will exit calculations at the step where we will obtain numerical convergence and the desired solution is presented in outline bar.

Table 10. Static structural solution

\begin{tabular}{|l|l|}
\hline Object Name & Solution (B6) \\
\hline State & Solved \\
\hline \multicolumn{2}{|l|}{ Adaptive Mesh Refinement } \\
\hline Max Refinement Loops & 1. \\
\hline Refinement Depth & 2. \\
\hline Information & \\
\hline Status & Done \\
\hline
\end{tabular}

Table 11. Solution information

\begin{tabular}{|l|l|}
\hline Object Name & $\begin{array}{l}\text { Solution } \\
\text { Information }\end{array}$ \\
\hline State & Solved \\
\hline Solution Information & \multicolumn{2}{|l|}{} \\
\hline Solution Output & Solver Output \\
\hline Update Interval & $2.5 \mathrm{~s}$ \\
\hline Display Points & All \\
\hline FE Connection Visibility & \\
\hline Activate Visibility & Yes \\
\hline Display & All FE Connectors \\
\hline $\begin{array}{l}\text { Draw Connections Attached } \\
\text { To }\end{array}$ & All Nodes \\
\hline Line Color & Connection Type \\
\hline Line Thickness & Single \\
\hline Display Type & Lines \\
\hline
\end{tabular}

\section{Linear Buckling Analysis}

Buckling is caused by a bifurcation in the solution to the equations of static equilibrium and Ansys software is designed to identify values for defined loads and geometry. Under axial load the pylon is able to sustain increasing load in one of two states of equilibrium: a purely compressed state (with no lateral deviation) or a laterally-deformed state.

Pylon buckling is characterized by a sudden sideways failure of a structural member subjected to high compressive stress.

Table 13. Linear Buckling Analysis

\begin{tabular}{|l|l|}
\hline Object Name & Linear Buckling (C5) \\
\hline State & Solved \\
\hline Definition & \\
\hline Physics Type & Structural \\
\hline Analysis Type & Linear Buckling \\
\hline Solver Target & Mechanical APDL \\
\hline Options & \\
\hline Generate Input Only & No \\
\hline
\end{tabular}

Table 14. Initial Condition Linear Buckling \begin{tabular}{l|l}
\hline Object Name & Pre-Stress (Static
\end{tabular} 


\begin{tabular}{|c|c|}
\hline & Structural) \\
\hline State & Fully Defined \\
\hline \multicolumn{2}{|l|}{ Definition } \\
\hline $\begin{array}{l}\text { Pre-Stress } \\
\text { Environment }\end{array}$ & Static Structural \\
\hline Pre-Stress Define By & Program Controlled \\
\hline Reported Loadstep & Last \\
\hline Reported Substep & Last \\
\hline Reported Time & End Time \\
\hline Contact Status & Use True Status \\
\hline
\end{tabular}

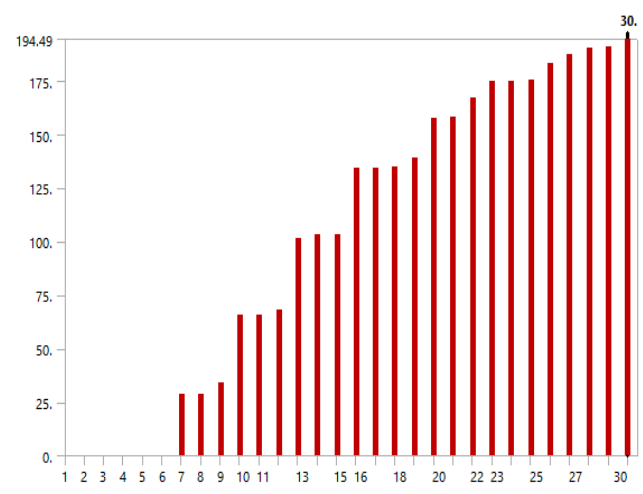

Table 15.Linear Buckling Analysis Settings

\begin{tabular}{|l|l|}
\hline Object Name & Analysis Settings \\
\hline State & Fully Defined \\
\hline Solver Type & Program Controlled \\
\hline Output Controls & \\
\hline Delete Unneeded Files & Yes \\
\hline Solver Units & Active System \\
\hline Solver Unit System & $\mathrm{mks}$ \\
\hline
\end{tabular}

\section{Solution}

Table 16 Linear Buckling Solution

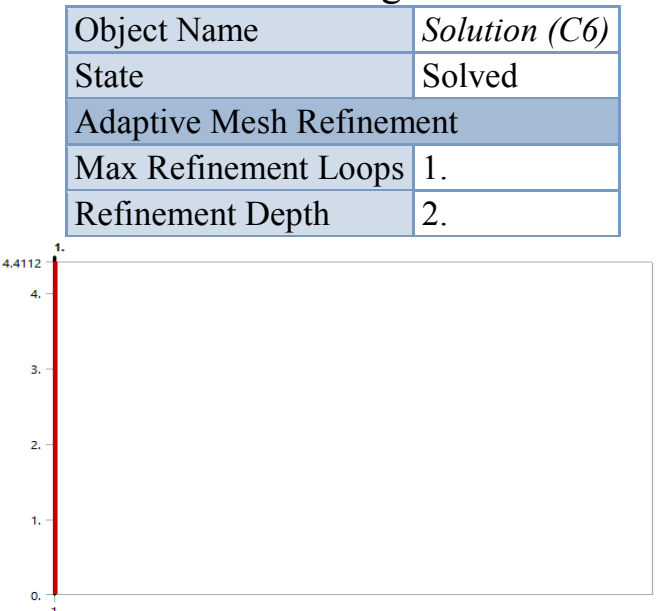

Fig.5. Linear Buckling Solution

Table 18. Linear Buckling Solution

Table 27. Modal solution

\begin{tabular}{|l|l|}
\hline Object Name & Solution (D6) \\
\hline State & Solved \\
\hline Adaptive Mesh Refinement \\
\hline Max Refinement Loops & 1. \\
\hline Refinement Depth & 2. \\
\hline Information & \\
\hline Status & Done \\
\hline
\end{tabular}

The following bar chart indicates the frequency at each calculated mode.

Fig. 6 Modal solution

TABLE 28 Modal Solution

\begin{tabular}{|l|l|}
\hline Mode & Frequency $[\mathrm{Hz}]$ \\
\hline 7. & 28.527 \\
\hline 8. & 28.558 \\
\hline 9. & 34.227 \\
\hline 10. & 65.49 \\
\hline 11. & 65.646 \\
\hline 12. & 68.059 \\
\hline 13. & 101.36 \\
\hline 14. & 103.19 \\
\hline 15. & 103.39 \\
\hline 16. & 134.27 \\
\hline 17. & 134.43 \\
\hline 18. & 134.6 \\
\hline 19. & 138.87 \\
\hline 20. & 157.64 \\
\hline 21. & 157.82 \\
\hline 22. & 166.99 \\
\hline 23. & 174.61 \\
\hline 24. & 174.96 \\
\hline 25. & 175.29 \\
\hline 26. & 182.89 \\
\hline 27. & 187.22 \\
\hline 28. & 190.4 \\
\hline 29. & 190.72 \\
\hline 30. & 194.49 \\
\hline & \\
\hline
\end{tabular}

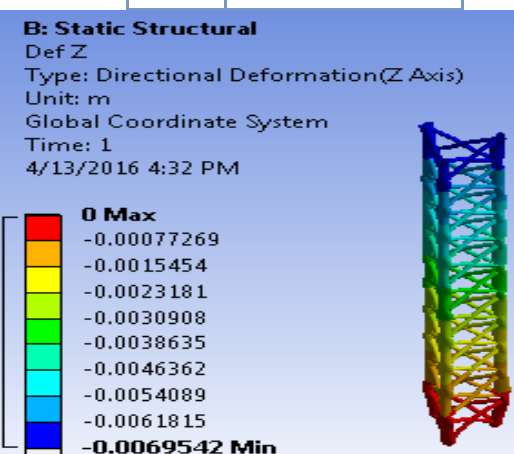

Fig. 7 Results in static structural on $Z$ axis 


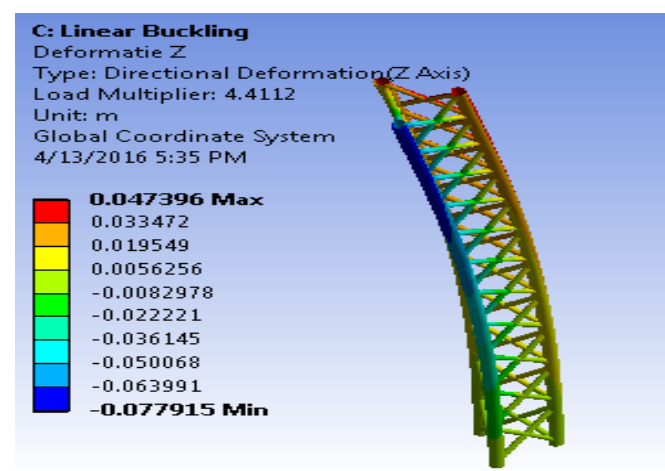

Fig. 8 Results in linear buckling on $Z$ axis

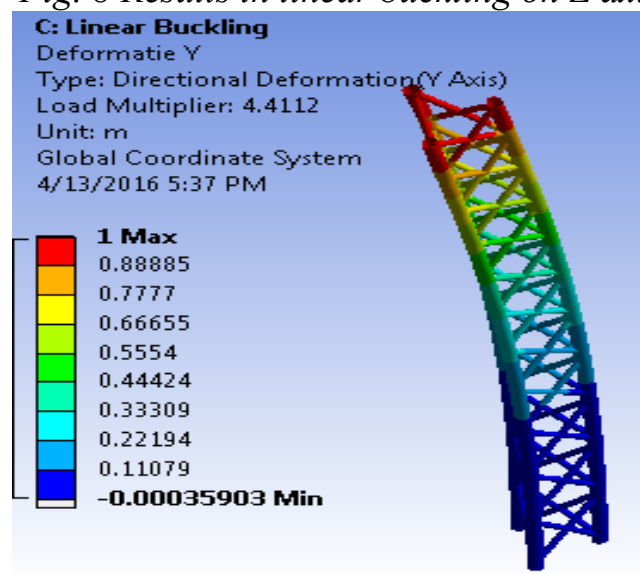

Fig.9 Results in linear buckling on Y axis

\section{Modal analysis results}

The modal analysis is used to determine the natural frequencies and mode shapes of the multipurpose pylon. We present several modes of vibration according to operational frequencies, but continuous like pylons have an infinite number of degrees of freedom. All data presented below in figures are natural frequencies and are a starting point for a transient or harmonic analysis [5].

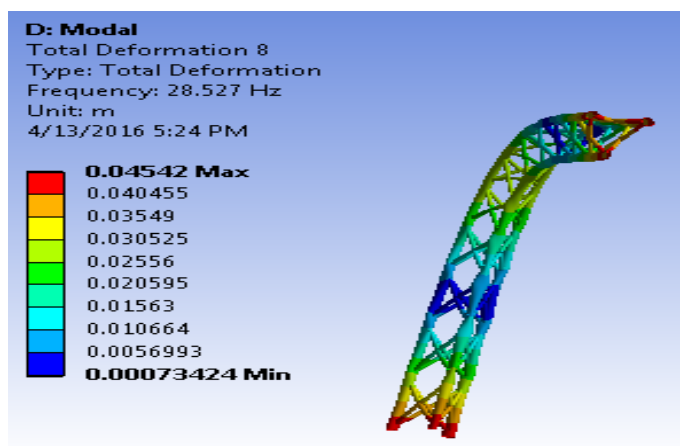

Fig. 10 Total deformation 8 results in modal analysis

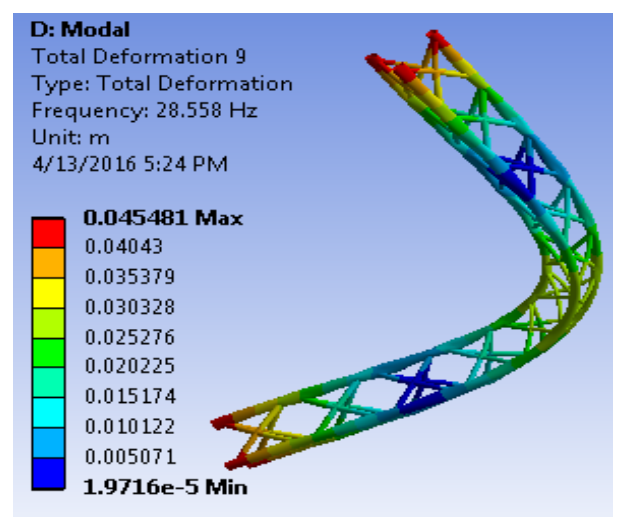

Fig.11 Total deformation 9 results in modal analysis

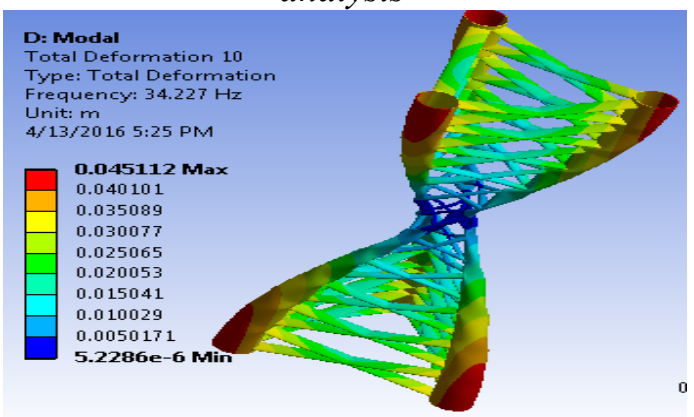

Fig. 12 Total deformation 10 results in modal analysis

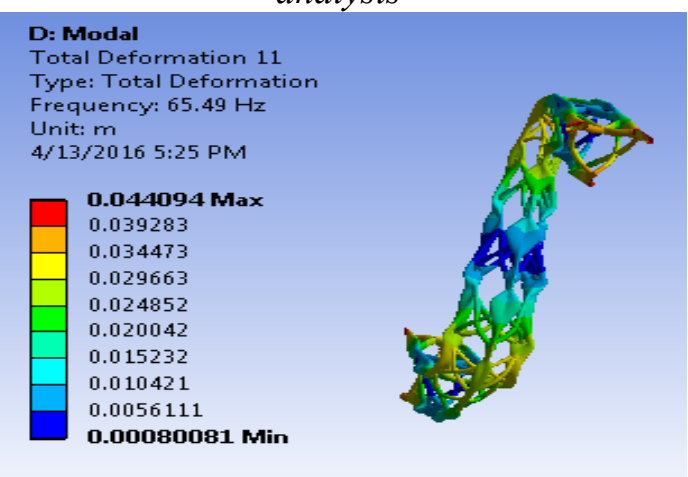

Fig. 13 Total deformation 11 results in modal analysis

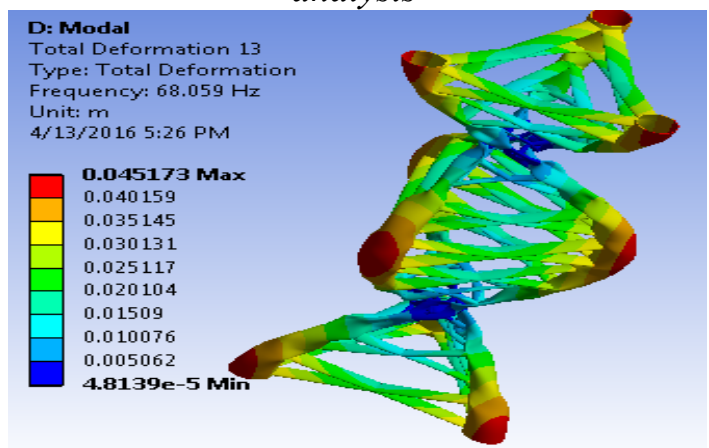

Fig. 14 Total deformation 13 results in modal analysis 


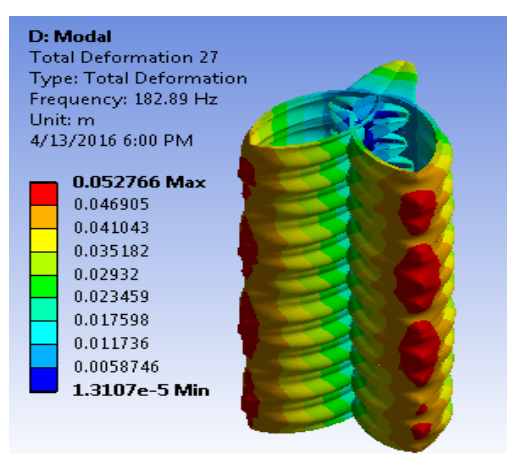

Fig.15 Total deformation 27 results in modal analysis

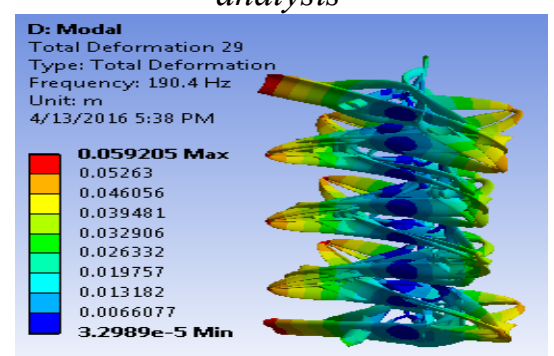

Fig. 16 Total deformation 29 results in modal analysis

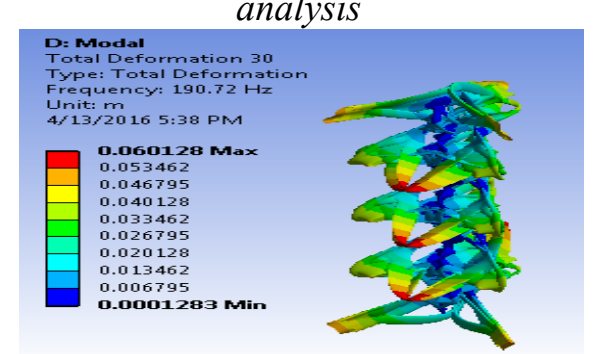

Fig. 17 Total deformation 30 results in modal analysis

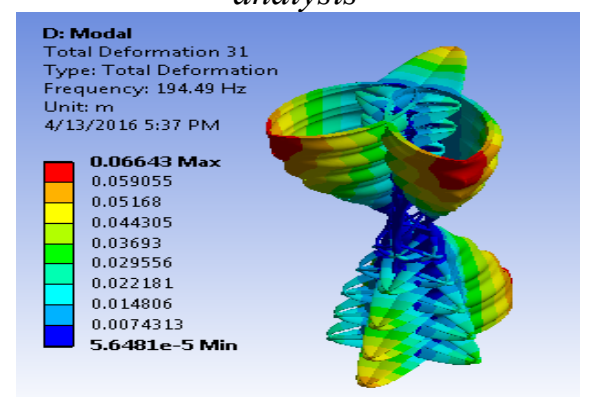

Fig. 18 Total deformation 31 results in modal analysis

\section{Conclusions}

This work has reviewed and reported the state-of-the-art research in 2016 on pylon design and software analysis in Naval Academy. In this analysis we have shown that the multi purpose pylon design is an evolutionary process on design parameters and strong software analysis.

The analysis presented in this paper can be further explored to develop multipurpose pylons for naval applications.

This paper has reviewed and reported the state-of-the-art research in ANSYS simulations for pylon analysis. In this analysis we have shown static structural, linear buckling and modal based on the presented input geometry parameters and strong software analysis.

The values presented for a triangular-shaped pylon based on simulated Ansys are well-defined parameters required in specific load analysis.

In this case the structure is subjected to the considered axial force of $1000[\mathrm{kN}]$ and all data presented for each simulation case can be used in further analysis. Considering stresses values, the configurations will withstand any military loads.

\section{References}

[1] Scurtu I.C., Manufacturing and design of the offshore structure Froude scale model related to basin restrictions, Paper ID: A-30, Modtech Conference2015, The Third International Conference on Modern Manufacturing Technologies in Industrial Engineering, Mamaia, Romania, June17-20, 2015.

[2] Scurtu I.-C., Pricop M., Babiuc B., Study of offshore structure design related to Ansys stress, displacement and vibration modes, Constanţa Maritime University Annals, Year XIV, Vol.22, ISSN 1582-3601, Constanţa, 2014.

[3] STAN L.-C., Offshore marine energy in the European area, Constanţa Maritime University Annals, Year XIV, Vol.24, ISSN 1582-3601, Constanţa, 2015. 
[4] STAN L.-C., Seas and oceans, suppliers of the new and innovative renewable energy, Constanţa Maritime University Annals, Year XIV, Vol.24, ISSN 1582-3601, Constanţa, 2015.

[5] http://www.ansys.com/Products 